\title{
Effect of advanced glycation end products, extracellular matrix metalloproteinase inducer and matrix metalloproteinases on type-I collagen metabolism
}

\author{
WANG LI ${ }^{1}$, WANG LING ${ }^{1}$, XIAOMEI TENG ${ }^{1}$, CUIXIA QUAN $^{1}$, SHENGNAN CAI ${ }^{1}$ and SHUQUN HU $^{2}$ \\ ${ }^{1}$ Department of Clinical Laboratory, Xuzhou First People's Hospital, Xuzhou, Jiangsu 221002; \\ ${ }^{2}$ Teaching and Research Section of Biochemistry, Xuzhou Medical College, Xuzhou, Jiangsu 221004, P.R. China
}

Received January 25, 2016; Accepted March 23, 2016

DOI: $10.3892 /$ br.2016.641

\begin{abstract}
The aim of the study was to examine the association among advanced glycation end products (AGEs), extracellular matrix metalloproteinase inducer (EMMPRIN) and matrix metalloproteinase (MMPs), and investigate whether AGEs affect type I collagen (COL-I) through EMMPRIN or MMPs. A co-culture system with the osteoblast-like cells (MC3T3E1) and mouse RAW264.7 cells was employed to examine the effects of AGE-bovine serum albumin (BSA) $(50 \mathrm{mg} / \mathrm{l})$, EMMPRIN antibody $(5 \mathrm{mg} / \mathrm{l})$ and AGE-BSA+EMMPRIN antibody separately on COL-I expression for $24 \mathrm{~h}$. Culture media were analyzed for the content of COL-I by ELISA. The effect of different concentrations of AGE-BSA $(0,50,100,200$ and $400 \mathrm{mg} / \mathrm{l})$ for $24 \mathrm{~h}$ was assessed on COL-I levels. Finally, semiquantitative RT-PCR was used to detect the osteoblast COL-I mRNA expression and MMP-2 and MMP-9's PMAO were also measured in the culture medium. COL-I content in the culture medium decreased significantly following treatment with AGE-BSA $(\mathrm{P}<0.05)$. EMMPRIN antibody increased COL-I content $(\mathrm{P}<0.05)$. EMMPRIN antibody+AGE-BSA increased COL-I significantly $(\mathrm{P}<0.05)$. Different concentrations of AGE-BSA increased COL-I mRNA expression significantly compared with the control group $(\mathrm{P}<0.05)$, and were enhanced with increasing AGE-BSA concentration $(\mathrm{P}<0.05)$. Also MMP-2 and MMP-9 secretion increased significantly $(\mathrm{P}<0.05)$, with the increasing AGE-BSA concentration. In conclusion, an increase in AGE levels in vitro stimulates the secretion of EMMPRIN/MMPs, promotes the degradation of COL-I and reduces bone strength.
\end{abstract}

Correspondence to: Dr Wang Li, Department of Clinical Laboratory, Xuzhou First People's Hospital, 19 Zhongshanbei Road, Xuzhou, Jiangsu 221002, P.R. China

E-mail: jsxzwdl@163.com

Key words: advanced glycosylation end products, type I collagen, matrix metalloproteinases, extracellular matrix metalloproteinase inducer

\section{Introduction}

Type I collagen (COL-I) is the main component of bone matrix and its main function is to absorb and transfer stress and is suitable for force deformation and tension maintenance (1). Matrix metalloproteinase (MMPs) is a major degradation enzyme system of extracellular matrix that can degrade extracellular matrix components such as collagen and elastin, but not polysaccharides (2). Synthesis and expression of MMPs are regulated by the extracellular matrix metalloproteinase inducer (EMMPRIN).

Previous findings $(3,4)$ have shown that advanced glycation end products (AGEs) may not support bone resorption to some extent, but reduces bone resorption and leads to osteoporosis. Additionally, patients with osteoporosis have a lot of AGEs accumulated in their tissues. The accumulation can decrease the mechanical properties of cortical bone and trabecular bone and increase osteopsathyrosis, and increases the risk of fractures (5).

In the present study, we examined the effect of the AGE-bovine serum albumin (BSA) in vitro on the osteoblast and osteoclast precursor cell co-culture system, and observed that COL-I expression is controlled by AGEs and the EMMPRIN/MMPs system.

\section{Materials and methods}

Cells and reagents. The American ABI, type 9700 polymerase chain reaction (PCR) machine was used in the present study [Applied Biosystems (ABI) Life Technologies, Foster City, CA, USA]. BSA was purchased from Amresco LLC (Solon, $\mathrm{OH}, \mathrm{USA}) ; \alpha$-minimum essential medium ( $\alpha$-MEM) from Gibco (Grand Island, NY, USA) and fetal bovine serum from Hangzhou Sijiqing Biology Engineering Materials Co., Ltd. (Hangzhou, China). Mouse COL-I ELISA kit was purchased from the American Research and Experimental Development Corporation. MMP-2 and MMP-9 reagents, and EMMPRIN antibody were purchased from Shanghai Senxiong Science and Technology Industrial Co., Ltd. (sc-25531; Shanghai, China). Mouse bone-forming cells (MC3T3E1) and mouse macrophage RAW264.7 cells were purchased from CAS Shanghai Life Science Institute (Shanghai, China). 
Table I. Effect of different AGE-BSA concentrations in a co-culture system on the expression of MMP-2 and MMP-9 and COL-I mRNA.

\begin{tabular}{|c|c|c|c|c|c|c|c|c|}
\hline \multirow[b]{2}{*}{ Items } & \multirow[b]{2}{*}{$\alpha$-MEM } & \multirow[b]{2}{*}{ BSA } & \multicolumn{6}{|c|}{ AGE-BSA } \\
\hline & & & 50 & 100 & 200 & 400 & $\begin{array}{c}\text { Osteoblast } \\
400\end{array}$ & $\begin{array}{c}\text { Osteoclast } \\
400\end{array}$ \\
\hline $\begin{array}{l}\text { COL-I/ } \beta \text {-actin } \\
\text { mRNA }\end{array}$ & $0.7 \pm 0.02$ & $0.7 \pm 0.02$ & $0.8 \pm 0.02^{\mathrm{a}, \mathrm{b}}$ & $0.9 \pm 0.03^{\mathrm{a}, \mathrm{b}}$ & $0.9 \pm 0.03^{\mathrm{a}, \mathrm{b}}$ & $1.4 \pm 0.05^{\mathrm{a}, \mathrm{b}}$ & $1.1 \pm 0.05^{\mathrm{a}, \mathrm{b}}$ & - \\
\hline $\begin{array}{l}\text { MMP-2 } \\
\left(\text { INT } x \mathrm{~mm}^{2}\right)\end{array}$ & $41.5 \pm 3$ & $40.9 \pm 3$ & $75.3 \pm 5^{\mathrm{a}, \mathrm{b}}$ & $117.6 \pm 10^{\mathrm{a}, \mathrm{b}}$ & $138.7 \pm 13^{\mathrm{a}, \mathrm{b}}$ & $158 \pm 15^{\mathrm{a}, \mathrm{b}}$ & $41.0 \pm 3^{\mathrm{a}, \mathrm{b}}$ & $38.9 \pm 3^{\mathrm{a}, \mathrm{b}}$ \\
\hline $\begin{array}{l}\text { MMP-9 } \\
(\text { INT x mm²) }\end{array}$ & $211 \pm 19$ & $144 \pm 15$ & $451.3 \pm 30^{\mathrm{a}, \mathrm{b}}$ & $578.9 \pm 39^{\mathrm{a}, \mathrm{b}}$ & $667.0 \pm 49^{\mathrm{a}, \mathrm{b}}$ & $751 \pm 55^{\mathrm{a}, \mathrm{b}}$ & $100.2 \pm 9^{\mathrm{a}, \mathrm{b}}$ & $72.1 \pm 5^{\mathrm{a}, \mathrm{b}}$ \\
\hline
\end{tabular}

${ }^{\mathrm{a}} \mathrm{P}<0.05$, compared with the $\alpha$-MEM group; ${ }^{\mathrm{b}} \mathrm{P}<0.05$, compared with BSA group. MMP, matrix metalloproteinase; AGE, advanced glycation end product; BSA, bovine serum albumin; $\alpha$-MEM, $\alpha$-minimum essential medium.

AGE-BSA preparation. The concentration of BSA was $5 \mathrm{~g} / 1$, and that of glucose was $50 \mathrm{mmol} / 1$, in sterile phosphate-buffered saline (PBS at pH 7.4). Solutions were kept at $37^{\circ} \mathrm{C}$ under sterile conditions and in the dark for 90 days. Unreacted glucose in PBS solution was removed by dialysis and the formed AGE-BSA was collected. Fluorescence spectrum scanning analysis with an excitation wavelength of $370 \mathrm{~nm}$, an emission wavelength of $440 \mathrm{~nm}$, and a slit of $3 \mathrm{~nm}$, was used for identification of the AGE. The glucose that did not contain BSA served as the negative control.

Cell culture and intervention. MC3T3E1 and RAW264.7 cells were cultured in $10 \%$ fetal bovine serum and $\alpha$-MEM at $37^{\circ} \mathrm{C}$ in a $5 \% \mathrm{CO}_{2}$ incubator. The cells were grown in logarithmic phase in 6-well plates and the RAW264.7 cells were transferred into transwells. When the cells grew to $80-90 \%$ confluency, the RAW264.7 cells were inoculated from the transwell to the well with MC3T3E1 cells. The cell growth was then synchronized by incubation in serum-free culture medium (starvation conditions) for $24 \mathrm{~h}$.

The co-cultured cells were treated using $50 \mathrm{mg} / \mathrm{l}$ AGE-BSA, $5 \mathrm{mg} / \mathrm{l}$ EMMPRIN antibody, and combined AGE-BSA and EMMPRIN antibody treatments, respectively, for $24 \mathrm{~h}$. The controls were treated with BSA (400 mg/l), for $24 \mathrm{~h}$ and the culture medium was collected to detect the levels of COL-I.

The cells were treated with different concentrations of AGE-BSA (0, 50, 100, 200 and $400 \mathrm{mg} / \mathrm{l})$ in a co-culture system with BSA $(400 \mathrm{mg} / \mathrm{l})$ as the control to examine the expression of COL-I. The cells and culture medium were collected after $24 \mathrm{~h}$ to detect the COL-I level and the secretion of MMP-2 and MMP-9.

Detection of COL-I in the culture medium by ELISA. Release of COL-I in the medium was measured using ELISA, as previously described (2).

Detection of osteoblast COL-I mRNA expression by RT-PCR. Following the treatments, total RNA of the cells was extracted using TRIzol one-step method. Total RNA ( $2 \mu \mathrm{l})$ was used for reverse transcription, employing primers for COL-I upstream, 5'-TCTCCACTCTTCTAGTTCCT-3', and downstream,
5'-TTGGGTCATTTCCACATGC-3' to amplify a 268 base pair (bp) length cDNA fragment. Primers used for $\beta$-actin were upstream, 5'-CGTGCGTGACATTAAAGAG-3', and downstream, 5'-CTGGAAGGTGGACAGTGAG-3', to amplify a 435 bp length DNA fragment. The RT-PCR condition used were: $94^{\circ} \mathrm{C}$ denaturation for $3 \mathrm{~min}$, and again at $94^{\circ} \mathrm{C}$ for $1 \mathrm{~min}$, annealing at $56^{\circ} \mathrm{C}$ for $1 \mathrm{~min}$, and extension at $72^{\circ} \mathrm{C}$ for $1 \mathrm{~min}$ for 30 cycles of amplification, followed by extension at $72^{\circ} \mathrm{C}$ for $10 \mathrm{~min}$

Gelatin zymography to detect MMP-2 and MMP-9 in the culture medium. Cell culture medium was processed for SDS-polyacrylamide gel electrophoresis and at low temperature $\left(4^{\circ} \mathrm{C}\right)$ for $2.5 \mathrm{~h}$. The gel was placed in $2.5 \%$ Triton $\mathrm{X}-100$ and washed for $1 \mathrm{~h}$ and the gel was soaked in incubation buffer $\left(50 \mathrm{mmol} / 1\right.$ Tris- $\mathrm{HCl}, 5 \mathrm{mM} \mathrm{CaCl}_{2}, 0.2 \mathrm{mmol} / \mathrm{l} \mathrm{NaCl}$, $0.02 \%$ Briji-35, pH 7.6; Shanghai Zhenxing Reagent Factory, Shanghai, China) at $37^{\circ} \mathrm{C}$ for $18 \mathrm{~h}$. The gel was then stained with coomassie brilliant blue and finally the MMP bands were visualized on a blue background and analyzed densitometrically.

Statistical analysis. SPSS 16.0 statistical software (SPSS, Inc., Chicago, IL, USA) was used to analyze data, and a comparison between groups was made using the Student-Newman-Keuls test. $\mathrm{P}<0.05$ was considered to indicate a statistically significant difference.

\section{Results}

Effect of AGE-BSA and EMMPRIN antibody. The effect of AGE-BSA and EMMPRIN antibody, as well as combined AGE-BSA and EMMPRIN antibody on COL-I content in a co-culture system is shown in Table I. Under basic conditions, COL-I secretion was observed in the culture medium. In the presence of $50 \mathrm{mg} / \mathrm{l}$ AGE-BSA for $24 \mathrm{~h}$, the content of COL-I decreased significantly. By contrast, the addition of antibody of EMMPRIN resulted in COL-I content increasing significantly, even in the presence of AGE-BSA $(\mathrm{P}<0.05)$.

Effect of different concentrations of AGE-BSA in the co-culture system on MMP-2 and MMP-9 secretion and COL-I mRNA 
expression. The addition of BSA had no effect on the relative expression of COL-I mRNA compared with the $\alpha$-MEM group $(\mathrm{P}>0.05)$. AGE-BSA at different concentrations $(50,100$, 200 and $400 \mathrm{mg} / \mathrm{l}$ ) increased the relative expression of COL-I significantly compared with the BSA and $\alpha$-MEM groups $(\mathrm{P}<0.05)$, and increased proportionally with the increase in the AGE-BSA concentration $(\mathrm{P}<0.05)$. Secretion of MMP-2 and MMP-9 increased significantly $(\mathrm{P}<0.05)$, and increased propotionally with the increase in the AGE-BSA concentration $(\mathrm{P}<0.05)($ Table I).

\section{Discussion}

COL-I is the most abundant structural protein in bone, accounting for $90 \%$ of organic matter, is a bone metabolic product and has the ability of adjusting bone metabolism. Procollagen type I carboxy-terminal propeptide (PICP) and COL-I procollagen type I amino-terminal propeptide (PINP) constitute the specific index of COL-I synthesis rate, although a daily rhythmicity (6) between PICP and PINP is present that should be taken into account when assessing COL-I levels. COL-I is easy to undergo non-enzymatic glycosylation and osteoporosis patients have a large amount of AGEs accumulated in their bodies, which can decrease the collagen content and cause BMD reduction and bone biomechanical changes, leading to osteoporosis. Thus AGEs are associated with the synthesis and degradation of COL-I (7).

The findings of the presetn study showed that in the co-culture system MC3TE1 expressed COL-I in the $\alpha$-MEM group. With the addition of AGE-BSA, COL-I gene expression increased in a concentration-dependent manner. At the same time, COL-I content in the culture medium of cells decreased with the increase in AGE-BSA concentration. These results are similar to those of the reports by Yamamoto and Ozono (7) and indicate that although the osteoblast synthesis of COL-I increased in the co-culture system, the total number of cells in vitro decreased. Previous studies (8) have shown that AGEs can increase the expression of EMMPRIN by MC3T3E1 cells and elevate the degradation of extracellular matrix.

MMPs are a class of proteases that hydrolyze many types of proteins in extracellular matrix in the presence of zinc ions. There are a variety of bone MMPs, of which MMP-2 was mainly formed by osteoblasts and secreted, while MMP-9 is mainly secreted by osteoclasts. The present study identified that MMP-2 and MMP-9 levels increased after the AGE-BSA addition, in a dose-dependent manner. Previous studies (9) also showed that the upstream products of MMP-2 and MMP-9 were increased by AGEs. When EMMPRIN was constrained, the content of MMP-2 and MMP-9 decreased significantly (10).
The findings of the present study show that antibody against EMMPRIN antagonizes MMP-2 and MMP-9, with increased content of COL-I in the culture medium. This result indicates that AGEs increase the secretion of MMP-2 and MMP-9 by promoting EMMPRIN expression, thereby promoting the degradation of COL-I.

In summary, AGEs can promote the in vitro secretion of MMP-2 and MMP-9, enhancing COL-I degradation. Although COL-I gene expression showed an increase, its degradation may be more than the synthesis. This tilts the balance between COL-I synthesis and degradation, and affects the metabolism of the bone matrix, reduces bone strength and causes pathogenesis of osteoporosis (11).

\section{References}

1. Liu J, Xu Z, Wang J, et al: The changes of metabolism of collagen type i in post-menopausal osteoporosis. Acta Anat Sin 33: 166-169, 2002.

2. Everts V, Korper W, Docherty AJ and Beertsen W: Matrix metalloproteinase inhibitors block osteoclastic resorption of calvarial bone but not the resorption of long bone. Ann N Y Acad Sci 878: 603-606, 1999.

3. Ji JD, Woo JH, Choi SJ, Lee YH and Song GG: Advanced glycation end-products (AGEs): A novel therapeutic target for osteoporosis in patients with rheumatoid arthritis. Med Hypotheses 73: 201-202, 2009.

4. Dong XN, Qin A, Xu J and Wang X: In situ accumulation of advanced glycation endproducts (AGEs) in bone matrix and its correlation with osteoclastic bone resorption. Bone 49: 174-183, 2011.

5. Hein G, Wiegand R, Lehmann G, Stein G and Franke S: Advanced glycation end-products pentosidine and $\mathrm{N}^{\varepsilon}$-carboxymethyllysine are elevated in serum of patients with osteoporosis. Rheumatology (Oxford) 42: 1242-1246, 2003.

6. Xie B, Chen Y and Liu H: The role of collagen in osteoporosis. Chin J Gerontol 29: 2057-2059, 2009.

7. Yamamoto $\mathrm{T}$ and Ozono K: Role of advanced glycation endproducts in adynamic bone disease. Clin Calcium 11: 1044-1047, 2001 (In Japanese).

8. Dai R, Jin H and Sun Z: Effect of advanced glycation end products on the gene expression of EMMPRIN in cultured mouse embryo/fetus calvaria fibroblasts. Jiangsu Med J 33: 913-915, 2007 (In Chinese).

9. Qin J, Wang Z and Bi S: Relationship between serum matrix metalloproteinase-2, serum matrix metalloproteinase-9,bone biochemical markers and bone mineral density in postmenopausal women. Chin J Osteoporos 15: 292-295, 2009.

10. Zhou J, Zhu P, Jiang JL, Zhang Q, Wu ZB, Yao XY, Tang H, Lu N, Yang Y and Chen ZN: Involvement of CD147 in overexpression of MMP-2 and MMP-9 and enhancement of invasive potential of PMA-differentiated THP-1. BMC Cell Biol 6: 25, 2005.

11. Xie B, Chen Y and Liu H: Effect of bone collagen in osteoporosis. Chin J Gerontol 29: 2057-2059, 2009. 